\title{
COMPOSIÇÃO PROXIMAL, COR E QUALIDADE LIPÍDICA DE QUEIJO AZUL FRESCO E MATURADO
}

\section{Proximal composition, color and lipid quality of fresh and matured blue cheese}

\author{
Jaqueline Laurindo ${ }^{I}$, Ivane Benedetti Tonial ${ }^{*}$, Naimara Vieira do Prado ${ }^{I}$, \\ Silvane Morés ${ }^{1}$, Fabiane Picinin de Castro Cislaghi ${ }^{1}$
}

\begin{abstract}
RESUMO
O queijo azul é considerado fresco aos 35 dias de maturação. Este mesmo queijo pode ser denominado tipo gorgonzola após 90 dias maturação, podendo sofrer variações em suas características físicas e físico-químicas. Objetivou-se, no presente estudo, comparar as variações nas características de cor e de composição físico-química de queijo azul fresco e maturado, bem como determinar os índices de qualidade lipídica. Foram separadas três repetições de um mesmo lote de queijo azul (0 dia), os quais foram submetidos às análises de cor $\left(\mathrm{L}^{*}, \mathrm{a}^{*}, \mathrm{~b}^{*}\right)$, físico-químicas (umidade, cinzas, proteínas, lipídeos, carboidratos e sódio) e perfil de ácidos graxos. As demais porções de queijo azul foram submetidas ao processo de maturação sob as mesmas condições de temperatura e umidade relativa do ar. Para as amostras de queijos maturadas (45 dias), foram realizadas as mesmas análises para efeito de comparação e alteração das características iniciais. Os resultados mostraram que o processo de maturação do queijo interferiu e alterou a cor, especialmente pelo desenvolvimento do fungo adquirindo coloração verde intensa. Os parâmetros físicoquímicos mostraram alterações significativas nos percentuais de umidade, cinzas e sódio. O perfil de ácidos graxos revelou alterações significativas no percentual de ácidos graxos, somatórios, razões e índices de qualidade lipídica, conferindo ao queijo maturado maior potencial aterogênico e trombogênico.
\end{abstract}

Palavras-chave: gorgonzola; Sistema L*, a*, b*; perfil lipídico.

1 Universidade Tecnológica Federal do Paraná (UTFPR), Linha Santa Bárbara, s/n, 85601-970, Francisco Beltrão, PR, Brasil. E-mail: ivane@utfpr.edu.br.

* Autor para correspondência. 


\begin{abstract}
Blue cheese is considered fresh at 35 days of maturation. This same cheese can be denominated gorgonzola type after 90 days of maturation, when it will be able to undergo variations in its physical and physical-chemical characteristics. The aim of this study was to compare the variations in the color and physico-chemical composition characteristics of fresh and mature blue cheese, as well as to determine the lipid quality indexes. Three replicates of the same batch of Blue cheese ( 0 day) were separated, which were submitted to the color analyses ( $\left.L^{*}, a^{*}, b^{*}\right)$, physicalchemical (moisture, ashes, proteins, lipids, carbohydrates and sodium) and fatty acid profile. The other portions of blue cheese were submitted to the maturation process under the same conditions of temperature and relative humidity of the air. For the mature cheese samples (45 days), the same analyzes were carried out for comparison effect and initial characteristics change. The results showed that the maturation process of the cheese interfered and altered the color, especially by the development of the fungus acquiring intense green coloration. In the physical-chemical parameters, the percentages of humidity, ashes and sodium showed significant changes. The fatty acid profile revealed significant alterations in the percentage of fatty acids, sums, ratios and indexes of lipid quality giving to mature cheese a greater atherogenic and thrombogenic potential.
\end{abstract}

Keywords: gorgonzola; System L*, a *, b *; lipid profile.

\section{INTRODUÇÃO}

O Penicillium roquefort é um fungo aeróbico, mesofílico, em que o $\mathrm{pH}$ ótimo de crescimento varia entre 5,5 e 7,5, sendo seus esporos de coloração esverdeada (LOURENÇO NETO, 2013). O crescimento deste tipo de mofo em queijo dá origem ao queijo denominado azul, que possui sabor e aroma agradável e específico pela degradação dos compostos do leite (SCOTT et al., 2002).

O queijo azul é considerado um alimento vivo, por mudar suas características constantemente conforme avança seu estágio de maturação (CPGC, 2015). O Penicillium roquefort produz lipases que degradam os triglicerídeos, liberando ácidos graxos livres através da ruptura da ligação éster. Esses ácidos graxos são $\beta$-oxidados, liberando água e formando cetoácidos que são descarboxilados por descarboxilases fúngicas e se convertem em metil-cetonas (principalmente 2-pentanona, 2-heptanona e 2-nonanona) que são compostos aromáticos responsáveis pelo sabor e aroma de queijo azul (FURTADO, 2013).

No Brasil, a diferença entre queijo azul e queijo tipo gorgonzola é o tempo de maturação. O queijo denominado de 'queijo azul' é maturado por 35 dias (BRASIL, 2007), enquanto queijo tipo gorgonzola deve ter um período de maturação de pelo menos 90 dias, segundo o Regulamento da Inspeção Industrial e Sanitária de Produtos de Origem Animal (BRASIL, 1952), e ainda deve apresentar textura aberta e corpo quebradiço, sem elasticidade, sem reter à faca quando cortado e dissolvendo-se quando consumido (FURTADO, 2003).

A composição físico-química de queijo tipo gorgonzola apresenta $48-52 \%$ de umidade; $28-30 \%$ de gordura no extrato seco; 20-22\% de proteínas (LOURENÇO NETO, 2013). Assim, o Regulamento Técnico de 
queijo azul (BRASIL, 2007) classifica este queijo como queijo gordo e de média a alta umidade.

A gordura do leite, que por sua vez é composta por ácidos graxos, é dependente de fatores como a alimentação do animal (CHILLIARD; FERLAY, 2004); estação do ano (CHION et al., 2010); altitude da região produtora de leite, uma vez que as pastagens são constituídas por diferentes vegetais nas diferentes altitudes refletindo na diferença da composição do leite, como gordura, minerais e cor (BUTIKOFER et al., 2002; COLLOMB et al., 2002). Para avaliação da qualidade da gordura em alimentos, Ulbricht; Southgate propuseram em 1991 cálculos matemáticos que determinam o potencial aterogênico e trombogênico dos alimentos. Estes cálculos são conhecidos como índice aterogênico (IA) e o índice trombogênico (IT) cuja finalidade é identificar o potencial de um alimento em contribuir para o surgimento de doenças cardiovasculares (ULBRICHT; SOUTHGATE, 1991).

A coloração desse tipo de queijo deve ser branco-creme (amarelada) apresentando as formações características verdes azuladas (BRASIL, 1952) que tende a ser modificada durante a maturação, com predominância de veias verdes, característica do desenvolvimento do Penicillium roquefort (DIEZHANDINO et al., 2016).

O presente estudo teve por objetivo comparar as variações físicas, físico-químicas e lipídicas decorrentes do crescimento fúngico antes e após a maturação de queijo azul.

\section{MATERIAL E MÉTODOS}

\section{Amostragem}

Foram separadas três repetições de um mesmo lote e tanque de queijo azul de uma indústria do Sudoeste do Paraná no mês de agosto de 2016. Uma porção de cada um destes queijos foi coletada no dia 0 (logo após a produção, antes de ser enviado para a câmara de maturação) e analisada quanto aos aspectos físico-químicos. A porção restante de cada queijo ficou maturando na câmara da indústria queijeira, seguindo o fluxograma de produção local, lado a lado na câmara para que todas as repetições estivessem sob as mesmas condições de temperatura e umidade relativa do ar. No $45^{\circ}$ dia de maturação, a parte restante de cada uma das repetições foi coletada e analisada nos mesmos critérios para verificar as diferenças nas características ocasionadas pela cura e crescimento fúngico. As análises físico-químicas foram realizadas em triplicata no complexo de laboratórios da Universidade Federal da Fronteira Sul campus Realeza e a cromatografia em fase gasosa no laboratório da Universidade Tecnológica Federal do Paraná - campus Francisco Beltrão.

\section{Caracterização físico-química e perfil de ácidos graxos}

Os queijos Azuis foram caracterizados quanto aos percentuais de umidade, cinzas, proteínas e sódio de acordo com a AOAC (1997); lipídeos e carboidratos, de acordo com o Instituto Adolfo Lutz (2008) e valor calórico conforme Tagle (1981).

Para análise do perfil de ácidos graxos, os lipídios foram extraídos a frio dos queijos pelo método de Bligh-Dyer (1959) e transesterificados para ésteres metílicos correspondentes de ácidos graxos pelo método da ISO 5509 (1978) com solução de n-hexano e hidróxido de potássio ( $2 \mathrm{~mol} / \mathrm{L})$ em metanol. Para a identificação dos ácidos graxos usouse a técnica de cromatografia em fase gasosa, utilizando cromatógrafo da marca Shimadzu GC 2010, equipado com injetor split/splitless marca AOC 20i Shimadzu e detector de ionização por chama; coluna capilar de sílica fundida, marca Supelco (F.S.CA.SP-2560), medindo $100 \mathrm{~m}$ x $0,25 \mathrm{~mm} \times 20 \mu \mathrm{m}$ de fase estacionária. 
O modo de injeção foi splitless, a temperatura do injetor foi de $260{ }^{\circ} \mathrm{C}$, a temperatura inicial da coluna de $140{ }^{\circ} \mathrm{C}$ nos primeiros 5 minutos, aumentando $2,4^{\circ} \mathrm{C}$ por minuto até atingir $240{ }^{\circ} \mathrm{C}$ por 17 minutos, com vazão do gás de arraste (hélio 5.0) de 1,21 mL/min, e detector de ionização de chama operando a $260{ }^{\circ} \mathrm{C}$ utilizando ar sintético e hidrogênio sendo o tempo total de corrida de 60 minutos.

A identificação dos ácidos graxos se deu por comparação do tempo de retenção do mix de padrão analítico da Sigma Aldrich identificado como 18919-1 AMP, o qual apresenta 37 padrões de metil ésteres de ácidos graxos e seus valores foram expressos e porcentagem de área de pico corrigido.

Os índices de qualidade lipídica, conhecidos como índices de aterogenecidade e trombogenecidade foram determinados de acordo com o especificado por Ulbricht e Southgate (1991), conforme as equações 1 e 2.

$$
\begin{aligned}
\mathrm{IA}= & {[(12: 0+(4 \times 14: 0+16: 0)] /} \\
& (\Sigma \mathrm{AGMI}+\Sigma \mathrm{n}-6+\Sigma \mathrm{n}-3)
\end{aligned}
$$

Equação 1 - (IA): Índice de aterogenicidade

onde:

12:0 - Ácido Láurico; 14:0 - Ácido Mirístico; 16:0 - Ácido Palmítico; $\Sigma$ AGMI - Somatório de ácidos graxos monoinsaturados; $\Sigma$ n-6 Somatório de ácidos graxos ômega $6 ; \Sigma \mathrm{n}-3$ - Somatório de ácidos graxos ômega 3.

$$
\begin{aligned}
\mathrm{IT}= & (14: 0+16: 0+18: 0) / \\
& {[(0,5 \times \Sigma \text { AGMI })+(0,5 \times \Sigma \mathrm{n}-6)} \\
& +(3 \times \Sigma \mathrm{n}-3)+(\Sigma \mathrm{n}-3 / \Sigma \mathrm{n}-6)]
\end{aligned}
$$

Equação 2 - (IT): Índice de trombogenicidade

onde:

14:0 - Ácido Mirístico; 16:0 - Ácido Palmítico; 18:0 - Ácido Esteárico; इAGMI Somatório de ácidos graxos monoinsaturados; $\Sigma$ n-6 - Somatório de ácidos graxos ômega 6; $\Sigma$ n-3 - Somatório de ácidos graxos ômega 3.

\section{Análise de cor}

A cor dos queijos foi obtida por colorímetro (Konica Minolta CR-400), empregando o sistema CIELAB (CIE - Comissão Internacional de Iluminação e LAB - coordenadas colorimétrica $L^{*}, a^{*}$ e $\left.b^{*}\right)$, com os valores de luminosidade $\left(\mathrm{L}^{*}\right)$ variando do branco $(L=100)$ ao preto $(L=0)$, coordenada vermelho $\left(+a^{*}\right)$ e verde $\left(-a^{*}\right)$ e coordenada amarelo $\left(+b^{*}\right)$ e azul $\left(-b^{*}\right)$ que variam de 0 a 60 de acordo com Minolta (1994). Para isso, os queijos foram macerados de forma a incorporar o mofo por toda a massa do queijo e assim obter homogeneidade da amostra.

\section{Tratamento dos dados}

Análise de variância (ANOVA) foi empregada nos dados para verificação dos pressupostos de normalidade e homocedasticidade e teste de Tukey e Kruskal Wallis (95\% de confiança) para comparação das médias foram aplicados nos dados dos parâmetros físico-químicos e perfil de ácidos na maturação do queijo azul (ACTION, 2014).

\section{RESULTADOS E DISCUSSÃO}

\section{Caracterização físico-química}

Os resultados em percentuais de cada componente avaliado são apresentados na Tabela 1.

De acordo com o percentual de umidade encontrado, o queijo azul, pode ser classificado como queijo de média umidade $(36 \%$ - 45,9\%) (BRASIL, 1996), com diferença significativa $(\mathrm{p}<0,05)$ antes e após a maturação. No entanto, valores superiores aos encontrados no presente estudo são afirmados por Lourenço Neto (2013) (48\% - 52\%) e Furtado (2013) (43\% - 45\% aos 40 dias de maturação).

O percentual de cinzas representa o conteúdo de elementos minerais de um alimen to (SILVA; QUEIROZ, 2009). Em queijos, o 
Tabela 1 - Caracterização físico-química e química em base úmida de queijo azul antes e após a maturação

\begin{tabular}{ccc}
\hline Parâmetros & $\begin{array}{c}\text { Queijo Azul Fresco } \\
\left(1^{\mathrm{o}} \text { dia maturação) }\right.\end{array}$ & $\begin{array}{c}\text { Queijo Azul Maturado } \\
(45 \text { dias de maturação) }\end{array}$ \\
\hline Umidade (\%) & $44,29 \pm 2,54^{\mathrm{a}}$ & $40,81 \pm 3,62^{\mathrm{b}}$ \\
Cinzas (\%) & $3,30 \pm 0,18^{\mathrm{b}}$ & $4,96 \pm 0,66^{\mathrm{a}}$ \\
Proteína (\%) & $21,67 \pm 1,21^{\mathrm{a}}$ & $21,34 \pm 1,30^{\mathrm{a}}$ \\
Lipídeos (\%) & $29,83 \pm 1,61^{\mathrm{a}}$ & $32,50 \pm 1,32^{\mathrm{a}}$ \\
Carboidratos (\%) & $0,97 \pm 2,95^{\mathrm{a}}$ & $0,38 \pm 2,50^{\mathrm{a}}$ \\
Valor Energético* & $362,20 \pm 6,18^{\mathrm{a}}$ & $382,31 \pm 11,69^{\mathrm{a}}$ \\
Na (g/100g) & $0,66 \pm 0,39^{\mathrm{b}}$ & $0,96 \pm 0,78^{\mathrm{a}}$
\end{tabular}

*(kcal/100g). Os resultados referem-se à média \pm desvio padrão das três repetições analisadas em triplicata. Letras iguais sobrescritas na mesma linha representam médias iguais $(p>0,05)$ pelo teste de Tukey.

maior percentual de minerais é representado pelo cálcio (cloreto de cálcio) e sal (cloreto de sódio) presentes naturalmente na matéria prima e/ou adicionados ao queijo durante o processamento (FURTADO, 2013). Após a maturação do queijo azul, foi possível verificar aumento $(\mathrm{p}<0,05)$ no teor de cinzas, com variação de $1,66 \%$, o que se explica pela concentração dos minerais pela perda de umidade dos queijos no processo de maturação. Valores semelhantes $(2,5 \%-4,6 \%)$ aos encontrados no presente estudo, para minerais totais, foram relatados por Manzi et al. (2007) em diferentes marcas de queijo Gorgonzola Italiano.

A quantidade de proteínas manteve-se constante $(p>0,05)$ nos queijos azul fresco e maturado. Diezhandino et al. (2015), ao avaliarem o percentual de proteínas em queijo azul Valdéon observaram valores de 34\% não diferindo estatisticamente ao longo da maturação (de 2 a 120 dias), o que indica que com o processo de cura, o percentual de proteína não é alterada para este tipo de queijo.

O percentual de lipídeos não apresentou diferença significativa $(\mathrm{p}>0,05)$ antes e após a maturação para os queijos azuis. Manzi et al. (2007) encontraram média de $27,9 \%$ de gordura em amostras de gorgonzola italiano, enquanto Diezhandino et al. (2015) relataram o valor de $57,29 \%$ de lipídeos em queijo azul Valdeón, mostrando que diferentes queijos azuis possuem diferentes teores de lipídeos, de acordo com sua característica.

O percentual de carboidratos não diferiu estatisticamente no queijo azul fresco e maturado, embora, de acordo com Lourenço Neto (2013), se esperasse uma redução na quantidade deste constituinte, uma vez que no processo de maturação, a lactose, o principal carboidrato do leite, é hidrolisada originando posteriormente o ácido láctico pelas bactérias lácticas. A exemplo disso, cita-se o estudo realizado por Diezhandino et al. (2015), onde no início do processo de maturação, o queijo azul Valdeón apresentou $0,78 \%$ de lactose e ao longo dos 120 dias de maturação o valor de lactose encontrado foi de $0,07 \%$. No presente estudo, talvez, uma nova avaliação num maior tempo de cura fosse necessário para que diferenças significativas deste parâmetro fossem visualizadas. Outro fator a se considerar para a não redução do percentual de carboidratos pode estar relacionado ao uso de microrganismos galactose negativo, os quais não são capazes de metabolizar a galactose, que se acumula no meio, ou seja, no queijo (FURTADO, 1998). 
Tendo em vista que nenhum dos macronutrientes (carboidratos, proteínas e lipídeos) variou significativamente na maturação, entre o queijo azul fresco e maturado, o valor energético destes queijos manteve o mesmo comportamento, ou seja, não variou significativamente a quantidade de kcal/ $100 \mathrm{~g}$ do produto. Em comparação a outros tipos de queijos, o valor energético do queijo azul é semelhante ao queijo Prato $(360,00$ kcal/100g) e Parmesão (453,00 kcal/100g) e superior ao queijo Minas Frescal $(264,00$ kcal/100g), Petit Suisse (121,00 kcal/100g) e Ricota (140,00 kcal/100g) (TACO, 2011).

Concomitantemente com o teor de cinzas, o teor de sódio aumentou com a maturação em queijo azul. O aumento na concentração de sódio pode ser resultado da redução da umidade destes queijos durante a cura. $\mathrm{O}$ Penicillium roquefort é um microrganismo que apresenta como característica a capacidade de tolerar altas concentrações de cloreto de sódio, e, neste sentido, em geral os queijos azuis são mais salgados que outros queijos (FURTADO, 2013).

\section{Perfil de ácidos graxos e índices de qua- lidade lipídica}

Um total de 25 ácidos de ácidos graxos foram identificados nos queijos azul fresco e maturado, e o perfil, somatório, razões e índices de qualidade lipídica são apresentados na Tabela 2.

Do queijo azul fresco em comparação ao maturado, houve diferença $(\mathrm{p}<0,05)$ no percentual de todos os ácidos graxos identificados, indicando que o processo de maturação interfere no percentual, somatórios, razões e índices de qualidade lipídica deixando o queijo com maior potencial aterogênico e trombogênico.

No processo de maturação do queijo, houve aumento significativo $(\mathrm{p}<0,05)$ no percentual de ácidos graxos saturados (AGS), poliinsaturados (AGPI), ômega-3 (N-3), com redução de monoinsaturados (AGMI) e ômega-6 (N-6).

Nos queijos avaliados, o maior percentual na composição de ácidos graxos é formado por AGS, principalmente ácido palmítico (16:0), esteárico (18:0) e mirístico(14:0). Dos AGMI, o predominante no queijo azul fresco e maturado foi o ácido oléico (18:1n-9c) e dos AGPI foi o ácido linoléico (18:2n-6c).

Perfil de ácidos graxos semelhantes ao relatado no presente estudo foi verificado por Guilherme (2010) que observou predominância de ácidos graxos saturados (12:0; $14: 0 ; 16: 0 ; 18: 0)$ na avaliação de queijo coalho, ricota, queijo mussarela e queijo prato e AGMI ((18:1n-9c).

Queijos de leite de ovinos também possuem características de ácidos graxos e perfil lipídico semelhantes com queijo de bovinos. Pellegrini et al. (2013) percebeu que apesar de haver diferenças entre o processamento e o tempo de maturação de queijo pecorino, feta e labneh de leite de ovelha, a maior parte dos ácidos graxos são saturados (10:0; 14:0; 16:0 e 18:0). E de acordo com Oliveira et al. (2009), em mussarela de búfala, os ácidos graxos predominantes também foram 16:0; 18:1n9c; 12:0 e 18:0. Assim, fica obvio constatar semelhança no perfil de ácidos graxos para os diferentes tipos de queijos.

Em queijo azul fresco e maturado, a razão de ácidos graxos (n-6/n-3) apresentou redução após 45 dias de cura, com diferença estatística $(p<0,05)$. Essa redução se deve à diminuição no percentual de ácidos graxos ômega-6 e incremento no percentual de ácidos graxos ômega-3 melhorando a razão n-6/n-3 conferindo benefícios à saúde com relação à prevenção de doenças. Segundo Valenzuela et al. (2011), quando associados o aumento da ingestão de ômega-3 e redução de ingestão de ômega-6, a prevenção a alguns tipos de câncer pode apresentar resultados expressivos. 
Tabela 2 - Perfil de ácidos graxos, somatório, razões e índices de qualidade lipídica de queijo azul fresco e maturado

\begin{tabular}{|c|c|c|}
\hline Ácidos Graxos & Queijo Azul Fresco (1º dia) & Queijo Azul maturado $\left(45^{\circ}\right.$ dia $)$ \\
\hline $4: 0$ & $0,55 \pm 0,01^{\mathrm{a}}$ & $0,37 \pm 0,01^{\mathrm{b}}$ \\
\hline $6: 0$ & $0,56 \pm 0,01^{\mathrm{a}}$ & $0,41 \pm 0,01^{\mathrm{b}}$ \\
\hline $8: 0$ & $0,54 \pm 0,01^{\mathrm{a}}$ & $0,44 \pm 0,01^{\mathrm{b}}$ \\
\hline 10:0 & $1,84 \pm 0,01^{\mathrm{a}}$ & $1,63 \pm 0,01^{\mathrm{b}}$ \\
\hline $12: 0$ & $2,76 \pm 0,01^{\mathrm{a}}$ & $2,59 \pm 0,01^{\mathrm{b}}$ \\
\hline $14: 0$ & $10,71 \pm 0,01^{\mathrm{a}}$ & $10,65 \pm 0,01^{\mathrm{b}}$ \\
\hline $\mathrm{X} 1$ & $0,53 \pm 0,01^{\mathrm{a}}$ & $0,52 \pm 0,01^{\mathrm{b}}$ \\
\hline $14: 1$ & $0,80 \pm 0,01^{\mathrm{a}}$ & $0,74 \pm 0,01^{\mathrm{b}}$ \\
\hline $15: 0$ & $1,09 \pm 0,01^{\mathrm{a}}$ & $1,10 \pm 0,01^{\mathrm{b}}$ \\
\hline $16: 0$ & $31,51 \pm 0,01^{\mathrm{b}}$ & $32,56 \pm 0,01^{\mathrm{a}}$ \\
\hline $\mathrm{X} 2$ & $0,55 \pm 0,01^{\mathrm{b}}$ & $0,56 \pm 0,01^{\mathrm{a}}$ \\
\hline $\mathrm{X} 3$ & $0,20 \pm 0,01^{\mathrm{a}}$ & $0,20 \pm 0,01^{\mathrm{a}}$ \\
\hline $16: 1$ & $1,43 \pm 0,01^{\mathrm{a}}$ & $1,36 \pm 0,01^{\mathrm{b}}$ \\
\hline $17: 0$ & $0,79 \pm 0,01^{\mathrm{b}}$ & $0,87 \pm 0,01^{\mathrm{a}}$ \\
\hline $17: 1$ & $0,25 \pm 0,01^{\mathrm{a}}$ & $0,24 \pm 0,01^{\mathrm{b}}$ \\
\hline 18:0 & $13,44 \pm 0,01^{\mathrm{b}}$ & $14,18 \pm 0,01^{\mathrm{a}}$ \\
\hline $18: 1 \mathrm{n}-9 \mathrm{t}$ & ND & $3,59 \pm 0,01$ \\
\hline $18: 1 \mathrm{n}-9 \mathrm{c}$ & $28,23 \pm 0,01^{\mathrm{a}}$ & $23,68 \pm 0,01^{b}$ \\
\hline $\mathrm{X} 4$ & $0,64 \pm 0,01^{\mathrm{b}}$ & $0,65 \pm 0,01^{\mathrm{a}}$ \\
\hline $18: 2 n-6 t$ & $0,29 \pm 0,01^{\mathrm{a}}$ & $0,27 \pm 0,01^{\mathrm{b}}$ \\
\hline $18: 2 \mathrm{n} 6 \mathrm{c}$ & $1,64 \pm 0,01^{\mathrm{b}}$ & $1,66 \pm 0,01^{\mathrm{a}}$ \\
\hline $20: 0$ & $0,20 \pm 0,01^{\mathrm{b}}$ & $0,21 \pm 0,01^{\mathrm{a}}$ \\
\hline $18: 3 n-6$ & $0,15 \pm 0,01^{\mathrm{a}}$ & $0,14 \pm 0,01^{\mathrm{b}}$ \\
\hline $18: 3 n-3$ & $0,43 \pm 0,01^{\mathrm{b}}$ & $0,45 \pm 0,01^{\mathrm{a}}$ \\
\hline $21: 0$ & $0,87 \pm 0,01^{\mathrm{b}}$ & $0,94 \pm 0,01^{\mathrm{a}}$ \\
\hline \multicolumn{3}{|l|}{ Somatórios } \\
\hline AGPI & $2,51 \pm 0,01^{\mathrm{b}}$ & $2,53 \pm 0,01^{\mathrm{a}}$ \\
\hline AGMI & $30,71 \pm 0,01^{\mathrm{a}}$ & $29,61 \pm 0,01^{\mathrm{b}}$ \\
\hline AGS & $64,86 \pm 0,01^{\mathrm{b}}$ & $65,95 \pm 0,01^{\mathrm{a}}$ \\
\hline $\mathrm{X}$ & $1,92 \pm 0,01^{\mathrm{a}}$ & $1,92 \pm 0,01^{\mathrm{a}}$ \\
\hline$n-6$ & $2,082 \pm 0,0006^{\mathrm{a}}$ & $2,078 \pm 0,0003^{\mathrm{b}}$ \\
\hline$n-3$ & $0,43 \pm 0,01^{\mathrm{b}}$ & $0,45 \pm 0,01^{\mathrm{a}}$ \\
\hline \multicolumn{3}{|l|}{ Razões } \\
\hline$n-6 / n-3$ & $4,84 \pm 0,01^{\mathrm{a}}$ & $4,64 \pm 0,01^{\mathrm{b}}$ \\
\hline AGI/AGS & $0,51 \pm 0,01^{\mathrm{a}}$ & $0,48 \pm 0,01^{\mathrm{b}}$ \\
\hline AGPI/AGS & $0,0387 \pm 1,30 \times 10-5^{\mathrm{a}}$ & $0,0383 \pm 0,00001^{\mathrm{b}}$ \\
\hline
\end{tabular}

Índices de aterogenicidade e trombogenecidade

$\begin{array}{lll}\text { IA } & 2,32 \pm 0,01^{\mathrm{b}} & 2,42 \pm 0,01^{\mathrm{a}} \\ \text { IT } & 3,11 \pm 0,01^{\mathrm{b}} & 3,30 \pm 0,01^{\mathrm{a}}\end{array}$

IA - índice de aterogenecidade; IT - índice de trombogenecidade. Os resultados referem-se à média da área do pico em percentual \pm desvio padrão das repetições analisadas em duplicata. Letras iguais sobrescritas na mesma linha representam médias iguais pelo teste de Tukey $(\mathrm{p}>0,05)$. AGPI: ácidos graxos poliinsaturados; AGMI: ácidos graxos monoinsaturados; AGS: ácidos graxos saturados; X: ácidos graxos não-identificados; n-6: ácidos graxos ômega-6; n-3: ácidos graxos ômega-3. AGPI/AGS: ácidos graxos insaturados/saturados; AGI/AGS: ácidos graxos poliinsaturados/saturados; n-6/n-3: ômega-6/ômega-3. 
Os índices de aterogenecidade e trombogenecidade apresentaram aumento significativo $(\mathrm{p}<0,05)$ após o período de maturação. Para estes índices não existe ainda, um parâmetro para comparação, no entanto, relata-se que quanto menor o valor numérico destes índices, menor o risco de agregação plaquetária e risco de doenças coronarianas em virtude da maior concentração de ácidos graxos anti-aterogênicos (TURAN et al., 2007).
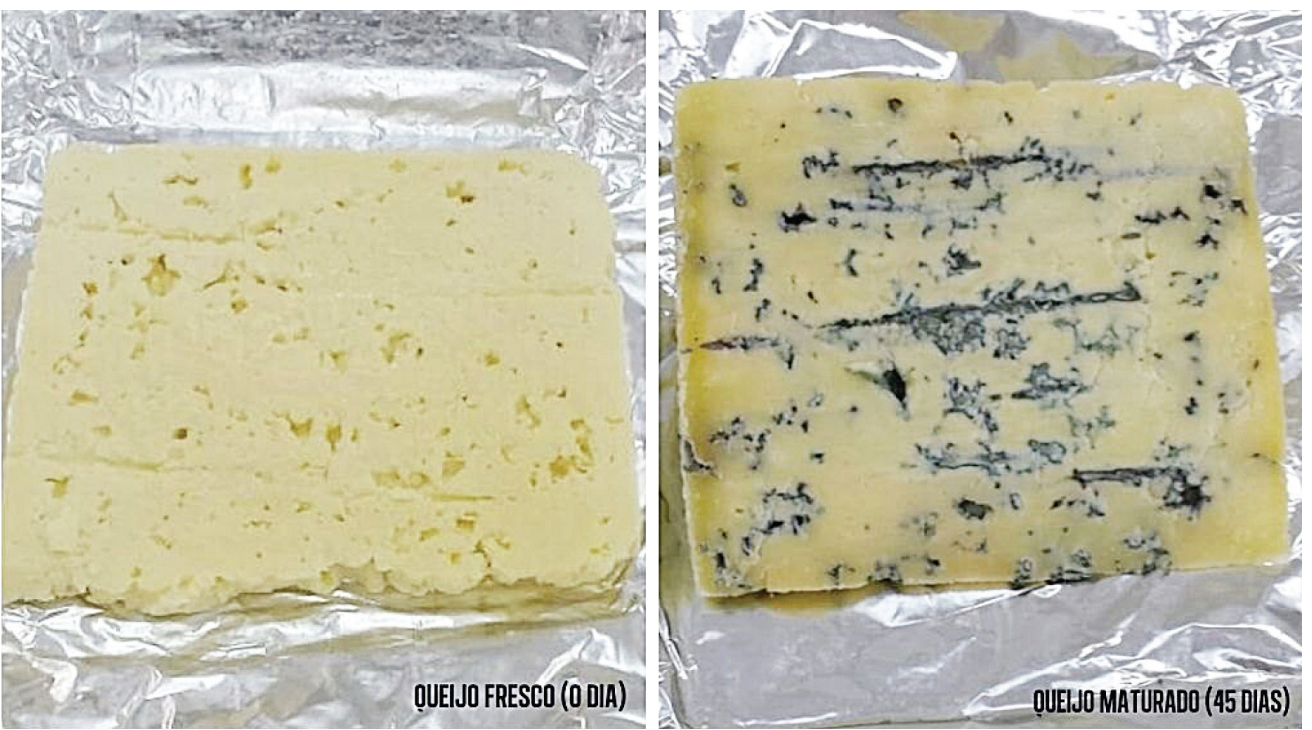

\section{Cor do queijo azul fresco e maturado}

A cor é uma das propriedades sensoriais que determina a aceitação ou recusa de um produto pelo consumidor (DIEZHANDINO et al., 2016). A Figura 1 mostra a coloração do queijo azul fresco e com 45 dias de maturação.

Os resultados da análise de cor em queijo azul antes e após a maturação são apresentados na Tabela 3.

Dos três parâmetros de cor avaliados no queijo azul fresco e maturado, o parâmetro luminosidade $(\mathrm{L})$ reduziu conforme houve

Figura 1 - Registro fotográfico das amostras de queijo azul fresco (0 dia) e maturado (45 dias)

Tabela 3 - Análise de cor em queijo azul fresco e aos 45 dias de maturação

\begin{tabular}{lccc}
\hline & \multicolumn{3}{c}{ Parâmetros de Cor } \\
\cline { 2 - 4 } Período de maturação & $\mathrm{L}^{*}$ & $\mathrm{a}^{*}$ & $\mathrm{~b}^{*}$ \\
\hline Fresco (1 dia) & $81,87 \pm 0,95^{\mathrm{a}}$ & $-4,52 \pm 0,14^{\mathrm{a}}$ & $34,31 \pm 0,67^{\mathrm{a}}$ \\
Maturado (45 dias) & $55,90 \pm 8,13^{\mathrm{b}}$ & $-5,64 \pm 0,20^{\mathrm{b}}$ & $13,55 \pm 3,55^{\mathrm{b}}$ \\
\hline
\end{tabular}

Os resultados referem-se a média \pm desvio padrão das repetições analisadas em triplicata. Letras iguais sobrescritas na mesma coluna representam médias iguais pelo teste de Tukey $(p>0,05)$. L* (Luminosidade); $+\mathrm{a}^{*}$ (vermelho), $-\mathrm{a}^{*}$ (verde); $+\mathrm{b}^{*}$ (amarelo), $-\mathrm{b}^{*}$ (azul). 
o desenvolvimento do Penicillium roquefort. Essa redução é decorrente do escurecimento causado pelas veias do mofo homogeneizadas na massa do queijo. O parâmetro - a* (coloração verde) aumentou após 45 dias de maturação do queijo, e o verde do queijo maturado mostrou maior predominância em relação ao amarelo $\left(+b^{*}\right)$. O queijo fresco apresenta uma coloração mais amarelada, enquanto que com o desenvolvimento e proliferação do fungo, a coloração verde fica mais intensa, o que pode ser visualizado pela redução do parâmetro $+b^{*}$ o que, de acordo com Diezhandino et al. (2016) resulta em uma melhor qualidade sensorial do produto.

Diezhandino et al. (2016) analisaram queijo azul espanhol (Valdeón Cheese), desde o $2^{\circ}$ até o $120^{\circ}$ dia de cura, onde a luminosidade inicial de 89,05 passou para 69,53 de média final, o valor médio de $\mathrm{a}^{*}$ reduziu de $-0,29$ para $-2,17$ e o valor médio de $b^{*}$ de 11,95 para 11,19 .

\section{CONCLUSÕES}

A caracterização físico-química mostrou que queijo azul possui alto teor de proteína e lipídeos e, consequentemente, alto valor energético. Após 45 dias de maturação, os parâmetros que sofreram alterações significativas foram: umidade, cinzas e sódio, assim como a cor, com redução de $\mathrm{L}^{*}$ e aumento da coloração verde sobre a cor amarela.

Em queijo azul, o perfil de ácidos graxos, assim como os somatórios, razões e índices de qualidade lipídica sofreram alterações com o processo de maturação, com aumento de AGD, AGPI e N-3 e redução de AGMI e N-6. Os índices de aterogenecidade e trombogenecidade foram menores no queijo azul fresco, indicando que seu consumo pode apresentar menor o risco em desenvolver doenças coronarianas. Assim, com base nos parâmetros de saudabilidade (teor de sódio, gordura, valor calórico, razões de ácidos graxos e índices de qualidade lipídica), pode-se concluir que o queijo azul deve ser consumido com moderação evitando a incidência de doenças proveniente de uma alimentação inadequada e calórica.

\section{AGRADECIMENTOS}

Os autores agradecem ao CNPq pelo suporte financeiro.

\section{REFERÊNCIAS}

ACTION Equipe Estatcamp (2014). Software Action. Estatcamp - Consultoria em estatística e qualidade, São Carlos - SP, Brasil. Disponível em: <http://www.portalaction. com.br>. Acesso em: 31 jan. 2018.

ASSOCIATION OF OFFICIAL ANALYTICAL CHEMISTS (AOAC). Official Methods of Analysis. $16^{\mathrm{a}}$ ed. Gaitherburg, v. 2, p. 1-43, 1997.

BLIGH, E. G.; DYER, W. J. A rapid method of total lipid extraction and purification. Canadian Journal of Biochemistry and Physiology, v. 37, p. 911-917, 1959.

BRASIL. Decreto $\mathrm{n}^{\circ}$ 30.691, DE 29 DE MARÇO DE 1952. Aprova o novo Regulamento da Inspeção Industrial e Sanitária de Produtos de Origem Animal. Diário Oficial da União, Rio de Janeiro, 29 mar. 1952.

BRASIL. Instrução Normativa $n^{\circ} 45$ de 23 de outubro de 2007. Adota o Regulamento Técnico de Identidade e Qualidade de Queijo azul, na forma do Anexo a presente Instrução Normativa. Diário Oficial da União, Brasília, DF, 24 out. 2007.

BRASIL. Portaria n ${ }^{\circ} 146$ de 07 de março de 1996. Apresenta o Regulamento Técnico de Identidade e Qualidade de Queijos. Diário 
Oficial da União, Brasília, DF, 11 mar. Seção 1, p. 3977. 1996.

BUTIKOFER, U. et al. Composition of Swiss highland and lowland Gruyere and L'Etivaz cheese, in preparation, 2002.

CHILLIARD, Y.; FERLAY, A. Dietary lipids and forages interactions on cow and goat milk fatty acid composition and sensory properties. Reproduction Nutricition Development, v. 44, n. 5, p.467-492, 2004.

CHION A.R. et al. Variation of fatty acid and terpene profiles in mountain milk and "Tomapiemontese" cheese as effected by diet composition in different seasons. Food Chemistry, v. 121, n. 2, p. 393-399, 2010.

COLlOMB, M. et al. Composition of fatty acids in cow's milk fat produced in the lowlands, mountains and highlands of Switzerland using high-resolution gas chromatography. International Dairy Journal, v. 12, n. 8, p. 649-659, 2002.

CPGC. Consortium for the protection of Gorgonzola Cheese. Disponível em: <http:// www.gorgonzola.com/>. Acesso em: 10 set. 2015 .

DIEZHANDINO, I. et al. Microbiological, physico-chemical and proteolytic changes I s Spanish blue cheese during ripening (Valdeón cheese). Food Chemistry, v. 168, n. 1, p. 134-141, 2015.

DIEZHANDINO, I. et al. Rheological, textural, colour ad sensory characteristics of a Spanish blue cheese (Valdeón cheese). Food Science and Technology, v. 65, p. 1118-1125, 2016.

FURTADO, S. C. Leveduras: uma fonte potencial de deterioração em alimentos.
Higiene Alimentar, São Paulo, v. 12, n. 54, p. 7-9, 1998.

FURTADO, M. M. Queijos Finos Maturados por Fungos. $1^{a}$ ed. São Paulo: MilkBizz, 2003. $128 \mathrm{p}$.

FURTADO, M. M. Queijos especiais. São Paulo: Setembro, 2013. 275 p.

GUILHERME, R. C. Perfil e qualidade nutricional dos lipídeos dos queijos Ricota, Coalho, Mussarela e Prato. 2010. 112 f. Dissertação (Mestrado em Nutrição) - Programa de Pós Graduação em Nutrição, Universidade Federal de Pernambuco, Recife, 2010 .

INSTITUTO ADOLFO LUTZ. Normas Analíticas do Instituto Adolfo Lutz: Métodos Químicos para Análise de Alimentos. $2^{\mathrm{a}}$ ed. São Paulo: Instituto Adolpho Lutz, 2008.

ISO - International Organization for Standardization. Geneve: Method ISO 5509, 1978.

LOURENÇO NETO, J. P. M. Queijos: aspectos tecnológicos. 1. ed. Juiz de Fora: Master Graf, 2013. 270 p.

MANZI, P. et al.Composizione di formaggi DOP italiani. La Rivista di Scienzadell' Alimentazione, v. 36, p. 9-22, 2007.

MINOLTA. Precise color communication: color control from feeling to instrumentation. Ramsey: Minolta Corporation Instrument Systems Division. 1994.

OLIVEIRA, R. L. Composição química e perfil de ácidos graxos do leite e muçarela de búfalas alimentadas com diferentes fontes de lipídeos. Arquivo Brasileiro de Medicina Veterinária e Zootecnia, v. 61, n. 3, p. 736744, 2009. 
PELLEGRINI, L. G. Caracterização físicoquímica e perfil lipídico de queijos produzidos com leite ovino. Revista Instituto Laticínio Cândido Tostes, v. 68, n. 394, p. 11-18, 2013.

SILVA, D. J.; QUEIROZ, A. C. Análise de alimentos métodos químicos e biológicos. $3^{\mathrm{a}}$ ed. Viçosa: Universidade Federal de Viçosa, 2009.

SCOTT, R. et al. Fabricación de Queso. $2^{\mathrm{a}}$ ed. Zaragoza: Acribia, 2002.

TACO - Tabela Brasileira de Composição de Alimentos. $4^{\mathrm{a}}$ ed. Campinas: UNICAMP, 2011.

TAGLE, M. A. Nutrição. São Paulo: Editora Artes Médicas. 1981. 233p.
TURAN, H. et al. Fatty acid profile and proximate composition of the thornback ray (Raja clavata, L. 1758) from the Sinop coast in the Black Sea. Journal of Fish Science, v. 1, n. 2, p. 97-103, 2007.

ULBRICHT, T. L. V.; SOUTHGATE, D. A. T. Coronary 38.heart disease: seven dietary factors. The Lancet, v. 338, n. 8773, p. 985992, 1991.

VALENZUELA, R. et al. Ácidos grasos ômega-3 y cáncer, una alternativa nutricional para su prevención y tratamiento. Revista chilena de nutrición, v. 38, n. 2, p. 219-226, 2011. 